Supporting Information

\title{
Electrodeposition of Nickel Hydroxide
}

\section{Nanoparticles on Carbon Nanotube Electrodes:}

\section{Correlation of Particle Crystallography with}

\section{Electrocatalytic Properties}

Sharel P. E, ${ }^{\dagger}$ Danqing Liu, ${ }^{\dagger}$ Robert A. Lazenby, ${ }^{\dagger}$ Jeremy Sloan, ${ }^{\ddagger}$ Marcio Vidotti,${ }^{\S}$ Patrick R. Unwin $^{* \dagger}$ and Julie V. Macpherson. ${ }^{* \dagger}$

${ }^{\dagger}$ Department of Chemistry and ${ }^{\ddagger}$ Department of Physics, University of Warwick, Coventry, CV4 7AL, United Kingdom

${ }^{\S}$ Departamento de Química, Universidade Federal do Paraná, CP 19032, CEP 81531-980

Curitiba, PR, Brazil

* To whom correspondence should be addressed. E-mail: p.r.unwin@warwick.ac.uk (P.R. Unwin), j.macpherson@warwick.ac.uk (J.V. Macpherson). 


\section{Contents}

Section S1. $\mathrm{Ni}(\mathrm{OH})_{2}$ nanoparticles (NPs) production via the direct and indirect approach

Section S2. Ethanol oxidation reaction (EOR) on $\beta$-Ni(OH $)_{2}$ NPs S6 modified SWNT network electrodes 


\section{Section S1. $\mathrm{Ni}(\mathrm{OH})_{2}$ nanoparticles (NPs) production via the direct and indirect approach}

Chronoamperometry in solutions containing $10 \mathrm{mM} \mathrm{Ni}\left(\mathrm{NO}_{3}\right)_{2}$ (direct approach) and $10 \mathrm{mM}$ $\mathrm{NiSO}_{4}$ (indirect approach) was used for $\mathrm{Ni}(\mathrm{OH})_{2} \mathrm{NP}$ deposition on SWNTs for both the direct and indirect approaches, as described in the main text. Typical current-time curves for a $5 \mathrm{~s}$ deposition are shown in Figure S1a for direct (blue) and indirect (red) deposition. For the direct approach, the electrodeposition current is due to $\mathrm{OH}^{-}$production. As seen, a stable current is achieved after a short time which corresponds to a constant flux of electrogenerated $\mathrm{OH}^{-}$. In the presence of $\mathrm{Ni}^{2+}$, supersaturation of the solution occurs resulting in $\mathrm{Ni}(\mathrm{OH})_{2}$ formation. It is possible to calculate the relative saturation ratio, $S:{ }^{1}$

$$
S=\left(a_{\mathrm{Ni}^{2+}} a_{\mathrm{OH}^{-}}\right) / K_{\mathrm{sp}}
$$

where $a_{\mathrm{Ni}^{2+}}$ and $a_{\mathrm{OH}^{-}}$are the activities of $\mathrm{Ni}^{2+}$ and $\mathrm{OH}^{-}$, and $K_{\mathrm{sp}}$ of $\mathrm{Ni}(\mathrm{OH})_{2}$ is $5.48 \times 10^{-16}$ at $25^{\circ} \mathrm{C}{ }^{2}$ Under constant flux conditions at the electrode surface, the electrogenerated $\mathrm{OH}^{-}$ concentration profile in the direction perpendicular to the electrode surface, can be calculated using equations (S2) and (S3): ${ }^{3}$

$$
\begin{aligned}
& C-C o=\frac{j o l}{D}\left\{\frac{D t}{l^{2}}+\frac{3 x^{2}-l^{2}}{6 l^{2}}-\frac{2}{\pi^{2}} \sum_{m}^{\infty} \frac{(-1)^{m}}{m^{2}} \exp \left(-\frac{D m^{2} \pi^{2} t}{l^{2}}\right) \cos \frac{m \pi x}{l}\right\} \\
& j o=\frac{i}{n F}
\end{aligned}
$$

where $C$ is the concentration and $C o$ is initial concentration; $j o$ is the flux and $i$ is the current density during electrodeposition; $D$ is the diffusion coefficient of $\mathrm{OH}^{-}$ions $\left(5.6 \times 10^{-5} \mathrm{~cm}^{2} \mathrm{~s}^{-1}\right)^{4}$, $l$ is the separation of electrode surface and a parallel boundary (set as $0.22 \mathrm{~cm}$; unrestricted diffusion from or to the electrode surface), $t$ is time, $x$ is distance from electrode, and $m$ is the number of points used (100) in the analytical expression. Using a time, $t=5 \mathrm{~s}$, the resulting $\mathrm{OH}^{-}$concentration profile is shown in Figure S1b (equations S2 and S3) along with the calculated S values ( $\square$ ), using equation S1, but approximating activity by concentration. The 
high $\mathrm{OH}^{-}$concentrations generated close to the electrode surface $\sim 2.5 \mathrm{mM}$, together with the bulk concentration of $\left[\mathrm{Ni}^{2+}\right]=10 \mathrm{mM}$, result in very high $\mathrm{S}$ values of $10^{8}-10^{9}$, resulting in spontaneous NP precipitation from solution.

For the indirect approach, the Ni NPs were first electrodeposited and then potential cycled in the range of $0.1 \mathrm{~V}$ to $0.5 \mathrm{~V}$ in $0.1 \mathrm{M} \mathrm{KOH}\left(5 \mathrm{mV} \mathrm{s}^{-1}\right)$ to promote the transformation of Ni NPs into $\mathrm{Ni}(\mathrm{OH})_{2}$ NPs (Figure S1c).

(a)

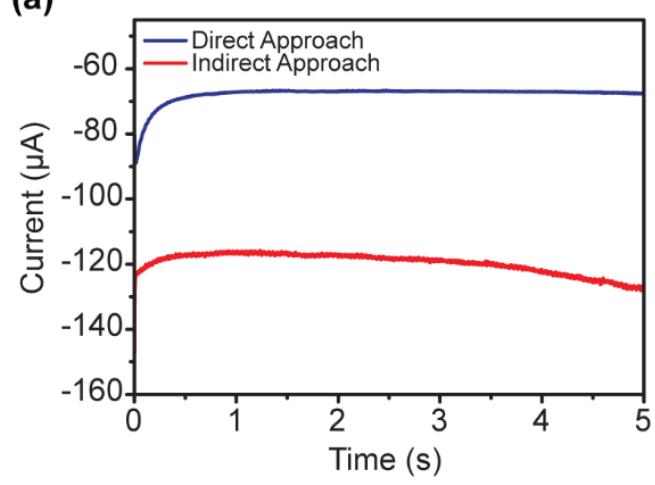

(b) Direct Approach

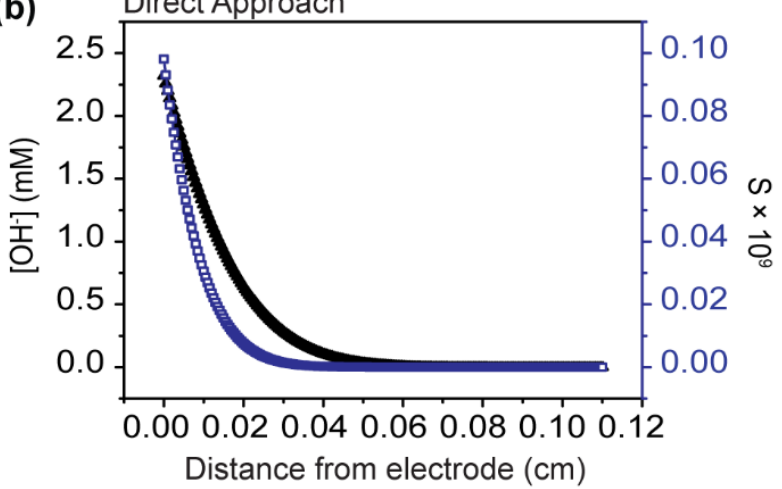

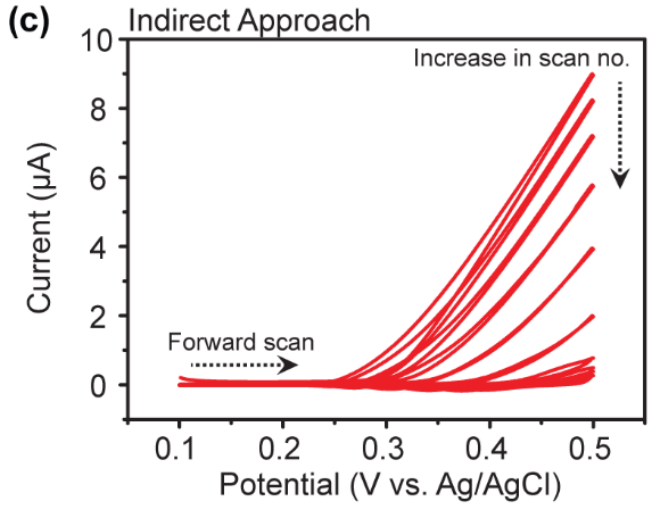

Figure S1. (a) Typical current-time curves recorded at a substrate potential of $-1.5 \mathrm{~V}$ for $5 \mathrm{~s}$ in $10 \mathrm{mM} \mathrm{Ni}\left(\mathrm{NO}_{3}\right)_{2}$ and $10 \mathrm{mM} \mathrm{NiSO}$ for the direct (blue) and indirect (red) approaches. (b) Concentration profile of $\mathrm{OH}^{-}(\boldsymbol{\Delta})$ vs. distance from electrode surface for a time of $5 \mathrm{~s}$ and corresponding S values ( $\square$ ), calculated using equation S1. (c) Repetitive CVs recorded in 0.1 $\mathrm{M} \mathrm{KOH}$ on Ni NP deposited SWNT network electrode (indirect approach). The scan rate was $5 \mathrm{mV} \mathrm{s}^{-1}$. 
Typical HRTEM-EDS of a typical sample showed the presence of Ni and O (Figure $\mathrm{S} 2 \mathrm{a}) . \mathrm{C}$ is associated with the SWNTs and lacey carbon supporting film, whilst $\mathrm{Cu}$ is a background signal from the grid which holds the lacey carbon film. The TEM-EDS interrogation size was a few hundred $\mathrm{nm} .1000 \mathrm{~s} \mathrm{Ni}(\mathrm{OH})_{2}$ deposition time was used to investigate the effect of possible Pt dissolution in alkaline solution of $50 \mathrm{mM} \mathrm{Ni}\left(\mathrm{NO}_{3}\right)_{2}$ (Figure S2b). This provides a reasonable time and concentration if such effects are 'exaggerated'. The SEM-EDS data ( hundred $\mu \mathrm{m})$ shows only $\mathrm{Ni}, \mathrm{O}, \mathrm{C}$ and $\mathrm{Si}$ (originated from the insulating substrate) proving the $\mathrm{Ni}(\mathrm{OH})_{2} \mathrm{NPs}$ deposition is not related to a Pt wire used as a counter electrode.
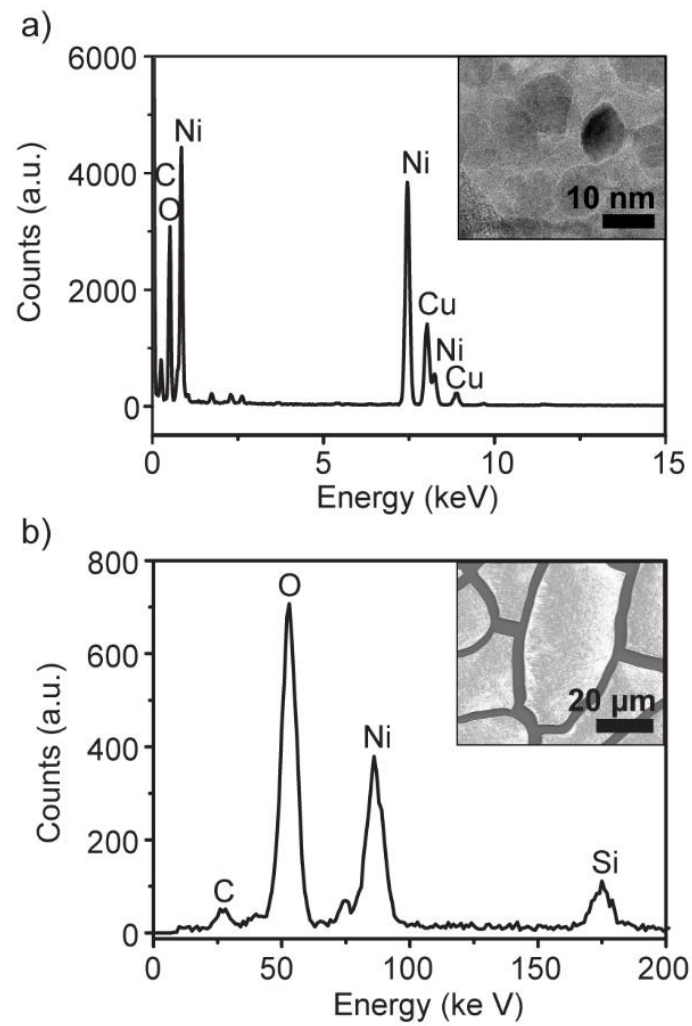

Figure S2. Typical EDS spectrum of the $\mathrm{Ni}(\mathrm{OH})_{2} / \mathrm{SWNT}$ produced by the direct approach with deposition parameters of (a) $5 \mathrm{~s} ; 10 \mathrm{mM} \mathrm{Ni}\left(\mathrm{NO}_{3}\right)_{2}$ solution; TEM-EDS and (b) $1000 \mathrm{~s}$; $50 \mathrm{mM} \mathrm{Ni}\left(\mathrm{NO}_{3}\right)_{2}$ solution; SEM-EDS, holding at $-1.5 \mathrm{~V}$ vs. $\mathrm{Ag} / \mathrm{AgCl}$. 
Section S2. Ethanol oxidation reaction $(\mathrm{EOR})$ on $\beta$-Ni(OH) $)_{2} \mathrm{NPs}$ modified SWNT network electrodes

Figure S3 shows a typical CV of EOR $(0.5 \mathrm{M} \mathrm{EtOH}))$ at $\beta$ - $\mathrm{Ni}(\mathrm{OH})_{2} \mathrm{NPs}$ supported on a HD SWNT network electrode prepared first by potential cycling Ni NPs, 10 times (black) and 50 times (red) in $0.1 \mathrm{M} \mathrm{KOH}$. Figure S2 clearly demonstrates that with increased potential cycling prior to measurement, the catalytic efficiency decreases. A 3.5 times lower current is seen at $+0.47 \mathrm{~V}$ vs. $\mathrm{Ag} / \mathrm{AgCl}$, which we attributed to NP aggregation and/or Ostwald ripening, resulting in larger sized nanostructures, ${ }^{5}$ which impacts the electrocatalytic activity. ${ }^{6}$

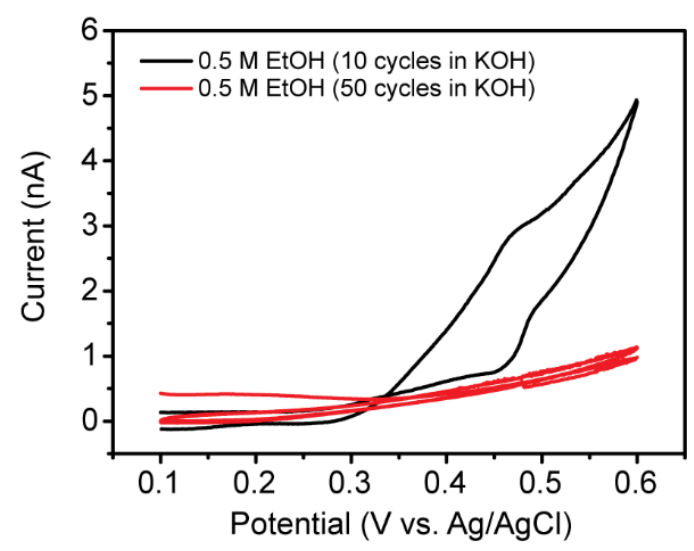

Figure S3. Typical CVs of $0.5 \mathrm{M}$ EtOH in $0.1 \mathrm{M} \mathrm{KOH}$ at $\beta-\mathrm{Ni}(\mathrm{OH})_{2} / \mathrm{SWNT}$ prepared by 10 (black) and 50 (red) potential cycles in $0.1 \mathrm{M} \mathrm{KOH}$. 


\section{REFERENCES}

(1) Hutton, L. A.; Vidotti, M.; Patel, A. N.; Newton, M. E.; Unwin, P. R.; Macpherson, J. V. Electrodeposition of Nickel Hydroxide Nanoparticles on Boron-Doped Diamond Electrodes for Oxidative Electrocatalysis. J. Phys. Chem. C 2011, 115, 1649-1658.

(2) Lide, D. R. Handbook of Chemistry and Physics; CRC Press: Boca Raton, FL, 2009.

(3) Crank, J. The Mathematics of Diffusion; Clarendon Press: Oxford, UK, 1975.

(4) Breiter, M.; Hoffmann, K. Z. Elektrochem. 1960, 64, 462.

(5) Marqusee, J. A.; Ross, J. Kinetics of Phase-Transitions-Theory of Ostwald Ripening. J. Chem. Phys. 1983, 79, 373-378.

(6) Da Silva, A. L. M.; Den Breejen, J. P.; Mattos, L. V.; Bitter, J. H.; De Jong, K. P.; Noronha, F. B. Cobalt Particle Size Effects on Catalytic Performance for Ethanol Steam Reforming - Smaller is Better. J. Catal. 2014, 318, 67-74. 